\title{
ODSLIK HRVATSKO-MAĐARSKIH DODIRA \\ U HRVATSKIM PREZIMENIMA
}

\section{UVOD}

\subsection{Ukratko o hrvatskim prezimenima i njihovu proučavanju}

Hrvatski prezimenski počeci sežu u 12. stoljeće - prezimena prvi dobivaju pripadnici višega staleža u urbanim sredinama istočnojadranskoga područja, a slijedom vremena prezimenski val zahvaća i ostale dijelove Hrvatske. Tridentski koncil (1545. 1563.) svojom odlukom vezanom uz obvezatnost vođenja matičnih knjiga, u koje se pojedinac upisuje osobnoimensko-prezimenskom formulom, pridonosi omasovnjivanju prezimenâ neovisno o staleškoj pripadnosti, prebivalištu i spolu njihovih nositelja. Jozefinskim patentom iz 80 -ih godina 18. stoljeća prezimena postaju općeobvezujućom identifikacijskom oznakom svakoga pojedinca.

Hrvatska prezimena imaju prilično ustaljenu i prepoznatljivu strukturu, dosadašnjim istraživanjima utvrđena je njihova čestotnost i razmještaj. Pretežiti se dio hrvatskih prezimena temelji na leksemima slavenskoga podrijetla te na inojezičnim posuđenicama prilagođenim hrvatskomu jezičnom sustavu. Za popisa pučanstva 2001. registrirana su 113192 prezimena, a na samome vrhu tablice čestotnosti bila su prezimena Horvat (22 225), ${ }^{1}$ Kovačević (15 835), Babić (13 150), Marić (10 617) i Novak (11 396) (Maletić - Šimunović 2008: 115). Gotovo istovjetan poredak ostao je i deset godina poslije. ${ }^{2}$

U novije je vrijeme sve rašireniji trend dvostrukih prezimena među kojima dominiraju ona ženskih osoba koje udajom svoje djevojačko prezime proširuju suprugovim. Prema Zakonu o osobnom imenu prezime se može sastojati od više riječi te se obvezatno nasljeđuje od roditelja (imaju li roditelji različita prezimena, dijete dobiva prezime jednoga od njih ili obaju). Prema Obiteljskome zakonu pri sklapanju braka svaki od supružnika može zadržati svoje prezime, može ga zamijeniti supružnikovim ili pak proširiti supružnikovim sam izabirući poredak prezimenskih sastavnica.

Hrvatska su prezimenima predmetom bavljenja jezikoslovaca različitih profila. Polazeći od činjenice da je prezime kompleksan sociolingvistički znak, najsvestranije

* Filozofski fakultet Sveučilišta u Zagrebu; Ulica Ivana Lučića 3, HR-10000 Zagreb, Hrvatska; afrancic@ffzg.hr

1 Broj u zagradi označuje broj nositelja dotičnoga prezimena.

2 Prema podatcima iz popisa stanovništva 2011., koje je objavio Državni zavod za statistiku, poredak prvih pet najčestotnijih prezimena bio je: Horvat, Kovačević, Babić, Marić, Jurić. http://www.dzs.hr/Hrv/censuses/census2011/results/htm/h01_01_31/H01_01_31.html. 
im pristupaju onomastičari - uzimajući u obzir jezične i izvanjezične čimbenike, nastoje proniknuti u njihovu etiologiju, dokazati vjerojatan poticaj njihove pojavnosti, iz njihova lika iščitati jezične značajke prostora na kojemu su nastala, vremena koje ih je oblikovalo te pomoću njih pratiti seobene putove njihovih nositelja.

Najopsežnije i najsadržajnije djelo o hrvatskim prezimenima napisao je Petar Šimunović (2006) koji je i suautorom troknjižja Hrvatski prezimenik : Pučanstvo Republike Hrvatske na početku 21. stoljeća (2008.) nastaloga na osnovi popisa pučanstva 2001. te autor mnogih radova manjega opsega u kojima s osobitim žarom $i$ akribijom vrsnoga onomastičara opisuje i tumači prezimena kao „narodnosne spomenike našega pamćenja“, „pouzdane poklade pučkoga poimanja stvarnosti“ $i$,,svjedoke nacionalnoga protega u prostoru i vremenu“".

\subsection{Hrvatski jezik kao jezik primalac u jezičnome posuđivanju s posebnim obzirom na hrvatsko-mađarske jezične dodire}

Spletom različitih povijesnih, društvenih i geopolitičkih okolnosti hrvatski jezik od najranije svoje povijesti dolazi u doticaj s drugim jezicima, što rezultira jezičnim posuđivanjem. Posuđivalo se iz unutarjezičnih i izvanjezičnih razloga, bilo izravno iz jezika u kojemu je riječ nastala, bilo preko jezika posrednika, a potvrđeni su i primjeri kružnoga posuđivanja. Budući da do posuđivanja najčešće dolazi na leksičkoj razini, središnje mjesto u kontaktološkim istraživanjima imaju leksičke posuđenice. Izloženost utjecaju drugih jezika vrlo je rano rezultirala jezičnim purizmom (u početku implicitnim, od druge polovice 18. stoljeća i eksplicitnim) kojim se nastojala očuvati jezična samobitnost i prepoznatljivost kao oblik nacionalne samobitnosti. Zbog svjesne jezične politike usmjerene protiv nepotrebnih posuđenica samo je dio posuđenih leksema sastavnicom hrvatskoga standardnog jezika, a znatno veći broj njih sreće se u nestandardnojezičnim govorima, koji su lišeni purističkih zahtjeva.

Tijekom povijesti u hrvatski jezik ulaze brojni latinizmi, grecizmi, talijanizmi, germanizmi, turcizmi, bohemizmi, srbizmi... U posljednje je vrijeme hrvatski, kao i drugi jezici, pod snažnim naletom anglizama. Među posuđenicama koje u različitim vremenima i različitim intenzitetom ulaze u hrvatski jezik, nezaobilazan je i spomen hungarizama - posuđenica kojima je mađarski jezik izvornik ili posrednik.

Doselivši se u Panonsku nizinu (koncem 9. stoljeća), Mađari dolaze u doticaj s Hrvatima, a od 1102. do 1918. pripadnici obaju naroda žive u istoj državnoj tvorevini, što u sklopu Ugarsko-Hrvatskoga Kraljevstva što u okviru Habsburške Monarhije i Austro-Ugarske. Osamstoljetne državne, političke, crkvene i gospodarske veze rezultirale su (obostranim) $)^{3}$ jezičnim posuđivanjem. Bunda, cipela, čipka, kečiga, korov, lopov; čardaš, gulaš, tokajac; fačuk, fela, japa, oblok, šor, fićfirić, mamlaz - samo su neki od leksema mađarskoga podrijetla koji se i danas rabe u hrvatskome jeziku. Mađarski se javlja i u ulozi jezika posrednika, vrlo često između hrvatskoga i njemačkoga (npr. beteg, frtalj, filir, herceg, huncut, perec, puška, roštilj, šaraf, šogor, vanjkuš). Brojnost hungarizama u hrvatskome jeziku pokazuje da genetske (mađarski pripada uralskoj, a

3 U radu će se, u sklopu teme, govoriti samo o mađarskim posuđenicama u hrvatskome jeziku. 
hrvatski indoeuropskoj jezičnoj porodici) i tipološke (mađarski je aglutinativan, hrvatski je flektivan jezik) razlike nisu bile znatnijom preprekom pri posuđivanju.

Hrvatsko-mađarski jezični dodiri isključivo su povijesni, a osobito su intenzivni od 13. do početka 17. stoljeća. Hungarizmi u navedenome razdoblju u hrvatski jezik ulaze u nekoliko valova zahvaćajući razne dijelove hrvatskoga područja i razne slojeve hrvatskoga leksičkog korpusa - među najranijim je posuđenicama kajkavska crkvena terminologija (npr. (j)eretnik 'heretik', pišpek 'biskup', plibanuš 'župnik', prošecija 'procesija', templom 'crkva'), a u kasnijim razdobljima posuđuju se leksemi koji pripadaju značenjskome krugu svakodnevnoga života i njegova predmetnog svijeta (ŽagarSzentesi 2005: 52-53). U 19. stoljeću, „zbog rastućeg purizma utjecaj mađarskoga poprima 'suptilniji' oblik: umjesto izravnog preuzimanja (uz samo nužne prilagodbe) mađarskih oblika, tipičnijim se pokazuju prevedenice“ (Žagar-Szentesi 2009: 77).

Povijest proučavanja hrvatsko-mađarskih jezičnih dodira počinje petojezičnikom Fausta Vrančića Dictionarium quinque nobilissimarum Europae linguarum, latinae, italicae, germanicae, dalmaticae et ungaricae (Venecija, 1595.), sastavnica kojega jest „Vocabula dalmatica quae Ungari sibi usurparunt ${ }^{4} .{ }^{4}$ Od brojnih radova nastalih u novije vrijeme, čiji autori tematiziraju mađarske posuđenice u hrvatskome, opsegom i važnošću izdvajaju se Ungarische Elemente im Serbokroatischen Lászla Hadrovicsa (1985.) te Ungarische Vorbilder der kroatischen Spracherneuerung Istvána Nyomárkaya (1989).

Dosadašnja su istraživanja pokazala da najviše hungarizama u hrvatskome jeziku pripada prostorno ograničenomu, dijelektnom, odnosno regionalnom leksiku (npr. oblok 'prozor', ašov 'štihača', beteg 'bolest', pajdaš 'prijatelj', jezero 'tisuću', čonta 'kost', falat 'komad'), nešto je manje arhaizma i historizama (npr. orsag 'zemlja, država', harmica 'carina', filir 'sitni kovani novac'), još su rjeđi hungarizmi čija se uporaba veže uglavnom uz kolokvijalni stil (npr. huncut 'prepredenjak, osoba spremna na sitne prijevare i nestašluke', fićfirić 'gizdelin, kicoš'), a tek mali broj njih sastavnicom je standardnoga jezika (Žagar-Szentesi 2005). Relativno mali broj hungarizama u standardnojezičnome leksiku ${ }^{5}$ dovodi se u vezu s činjenicom da državno zajedništvo s Mađarima nije bilo bezrezervno prihvaćano, što je rezultiralo otporom prema preuzimanju mađarskih riječi te uopće purističkim odnosom prema posuđenicama.

Što se tiče arealne zasvjedočenosti hungarizama, pretkazivo ih je najviše na hrvatskome sjeveru - duž čitavoga protega hrvatsko-mađarske granice - u kajkavštini i u štokavskim govorima slavonskoga dijalekta. Kudikamo je skromniji njihov udio u čakavštini, kamo su dospjeli kajkavskim posredništvom.

4 Istraživanje je pokazalo da je veliku većinu riječi Vrančić dobro uvrstio u mađarske kroatizme (npr. brat, golub, kovač, petak, sloboda, sreća, subota), ali da među njima ima i hrvatskih hungarizama (npr. beteg, rusag, šišak, kadmen, kip) (Meršić - Gulešić 1997; Gulešić 1998: 255).

5 Marija-Ana Dürrigl (1988) spominje ih četrdesetak, dok Milvia Gulešić (1998) drži da ih je znatno više napominjući „da je moguće odrediti samo približan, a ne i točan broj hungarizama u hrvatskome standardnom jeziku“. 


\subsection{Odraz hrvatsko-mađarskih jezičnih dodira u hrvatskoj onimiji}

Među 850 hungarizama što ih László Hadrovics u svojoj već spomenutoj monografiji Ungarische Elemente im Serbokroatischen popisuje, određuje im značenje, navodi brojne potvrde iz povijesnih pisanih izvora te etimološki raščlanjuje, 40 je imena. Dominiraju osobna imena (njih 27) - osim triju ženskih (Ilona, Katalina, Oršola), sva su ostala muška (Andraš, Antal, Benedik, Bernad, Bertolom, Endre, Farkaš, Ferenc, Gabor, Gal, Imre, Ištok, Ištvan, Januš, Kelemin, Lacko, Lajuš, Laslo, Matijaš, Mihal(j), Miklouš, Pongrac, Šandor, Žigmund). Imenske natuknice čini i devet etnonima (Horvat, Lenđel, Mađar, Rac, Sekelj, Serečen, Španjol, Tot, Totar) te tri toponima (Egiptom, Erdelj, Siget).

I letimičan pogled na suvremenu hrvatsku ojkonimiju pokazuje da su njezinim dijelom imena koja odaju vezu s jezikom sjevernih susjeda (npr. Madžarevo, Madžari, Andraševec, Banfi, Daruvar, Hercegovac, Vukovar, Bjelovar, Varaždin, Laslovo, Brodski Varoš, Cetinski Varoš, Berek, Darda, Farkaševac, Harmica, Horvati, Hodošan, Čakovec). Hungarizama ima i u imenima gradskih četvrti: Split ima svoj Veli Varoš, u Zagrebu je Siget, Retfala je jedna od osječkih gradskih četvrti, a među njegovim prigradskim naseljima nalaze se Sarvaš i Tenja... Hungarizmi su sastavnicom hrvatske mikrotoponimije (npr. Mezova, Sigetec), a mađarizirani likovi svetačkih imena, kojima se imenuje uglavnom starija populacija, mogu se čuti u neslužbenoj komunikaciji (npr. Eržika, Feri, Gabor, Ilka, Imbra, Jandraš, Janoš, Joška, Karči, Mihalj, Pišta, Židor, Žofa, Žuža), sastavnicom koje su i na hungarizmima temeljeni obiteljski nadimci (npr. Bačekovi, Bedenekovi, Čordoševi, Feljetorovi, Kenjevorjevi, Loščijovi, Ljenartovi, Pekovi, Remušovi, Saboljecevi, Štvanekovi) itd.

Osim spontanoga, iz međujezičnoga dodira proizišloga, unosa hungarizama u hrvatski jezik, povijest bilježi i nasilnu, političkim razlozima potaknutu, hungarizaciju. Npr. potkraj 19. stoljeća stubokom se mijenja onovremeni službeni međimurski ojkonimikon (npr. Čukovec > Drávasiklós, Dekanovec > Dékánfalva, Dragoslavec Selo > Delejes, Jalšovec > Erzsébetlak, Knezovec > Gyümölcsfalva, Sveta Marija > Muraszentmária). Nakon sloma mađarske vlasti, međimurskim se naseljima vraćaju njihova prvotna imena (Frančić - Žagar-Szentesi 2008).

\section{HRVATSKA PREZIMENA - SVJEDOCI HRVATSKO-MAĐARSKIH DODIRA}

Bez pretenzija za iscrpnim popisom prezimena koja sadržavaju mađarski element a sastavnicom su hrvatskoga prezimenskog korpusa te detaljnom raščlambom svih aspekata posuđivanja i njihovih osvjedočenja, $u$ radu će se u osnovnim crtama prikazati ta prepoznatljiva sastavnica hrvatskoga prezimenika. Prikaz će obuhvatiti podjelu na osnovne motivacijsko-semantičke skupine i navođenje odabranih primjera za svaku od njih te tvorbenu raščlambu također popraćenu ilustrativnim primjerima. Kao izvor građe poslužili su hrvatski prezimenici nastali na temelju popisa stanovništva sredinom 20. stoljeća (Šimunović - Putanec 1976) i početkom 21. stoljeća (Šimunović - Maletić 2008).

Prezimenske potvrde odaju različite stupnjeve prilagodbe hungarizama hrvatskomu jezičnom sustavu. Raspon tih prilagodbi jest od (rijetkih) potpuno neprilagođenih 
leksema (npr. Kocsis, Nagy, Szegedi, Szabo), preko leksema iz kojih se iščitava grafijsko-fonološka prilagodba (npr. Balaž, Čordaš, Erdelji, Mesaroš), do tvorenica prepoznatljivim hrvatskim prezimenskim sufiksima (npr. Janošević, Katanec, Sabolčić, Vargek). Katkad su potvrđene različite varijante istoga ishodišnog leksema (npr. Biro, Birov; Paler, Palir; Szabo, Sabo, Sabol; Šipoš, Šipuš). Varijantnost može, uz ostalo, biti posljedicom neprovedene transgrafemizacije ili različite transfonemizacije, varijantni leksemi mogu biti odrazom različitih stupnjeva razvoja mađarskoga vokalnog sustava, odnosno različitih razdoblja posuđivanja, a nije isključena ni svojevoljna intervencija zapisivača prezimena $u$ ranijim razdobljima.

\subsection{Motivacijsko-semantička klasifikacija prezimena}

Polazeći od tradicionalne podjele prezimenske građe na četiri osnovne motivacijsko-semantičke skupine - koju je u hrvatskoj onomastici osobito popularizirao Petar Šimunović prikazujući ih kao odgovore na pitanja čiji si, kakav si, otkud si i što si-svekoliki prezimenski korpus s očitom mađarskom sastavnicom dijeli se na:

\section{a) prezimena od osobnih imena ${ }^{6}$}

Antal, Antalašić, Antol, Antolić, Antolković, Jantolek (: Antal, Antonius); Balaš, Balaško, Balaž, Balažin, Balažinec (: Balász, Blasius); Balent, Balentić, Balentović (: Bálint, Valentinus); Ferenc, Ferenčić, Ferić, Ferko, Ferković (: Ferenc, Franciscus); Ištok, Ištvan, Ištvanić, Štvanek (: István, Stephanus); Januš, Janušek, Janušić (: János, Johannes); Jeđud, Jeđut (: Egyed, Aegidius); Katalin, Katalinić (: Katalin, Catharina); Kelemen, Kelemenić (: Kelemen, Clemens); Lajoš (: Lajos, Ludovicus); Lukacs, Lukač, Lukačević, Lukačić (: Lukács, Lucas); Matjaš, Matjašec (: Mátyás, Matthias); Pal, Palfi (: Pál, Paulus); Pongrac, Pongračić (: Pongrác, Pancratius); Šandor, Šandorović (: Sándor, Alexander)...

Osobna imena iščitana iz prezimenskih likova pripadaju gotovo isključivo svetačkomu repertoaru. Građa svjedoči i o dominaciji muških osobnih imena u prezimenskim osnovama, što je odslik patrijarhalnoga ustroja društva.

\section{b) prezimena od nadimaka}

Balog, Balogović (: balog 'ljevak'); Barat (: barát 'prijatelj; redovnik'); Barna (: barna 'smeđ'); Čonka, Čonkaš (: csonka 'krnj, sakat'); Feher, Fehir (: fehér 'bijel'); Fekete, Feketić (: fekete 'crn'); Kedveš (: kedves 'drag'); Kiš (: kis 'malen; mlad'); Kopas, Kopasić (: kopasz 'ćelav'); Nad, Nagy (: nagy 'velik'); Nađfej (: nagy 'velik' + fej 'glava'; 'glavat; pametan'); Šantalab, Šantavec (: santa ‘šepav, hrom; šepavac', láb 'noga'); Šarkanj (: sárkány 'zmaj'); Šovanj (: sovány 'mršav'); Vereš '(: vörös 'crven')...

6 Zbog ograničenoga prostora donose se samo odabrane prezimenske potvrde, tj. ne navode se prezimena tvorena od svih mađarskih likova osobnih imena koji se nalaze u hrvatskome prezimeniku niti sva prezimena koja se dovode u vezu s istim osobnim imenom. Na prvome je mjestu u zagradi temeljni mađarizirani, a na drugome latinski (ili latinizirani) lik osobnoga imena. Ako je isto osobno ime ugrađeno u veći broj prezimenskih likova, motivirajuće ime donosi se nakon posljednjega u nizu prezimena njime motiviranoga. 
Među nadimačkim prezimenima uočljivi su uobičajeni doprezimenski nadimački sadržaji koji se znatnim dijelom odnose na tjelesne i karakterne osobine.

\section{c) prezimena od etnika i etnonima}

Belovari (: Belovár 'Bjelovar'); Bočkaj (: Bocska); Budimac, Budimčić (: Budim); Cegledi (: Cegléd); Čanadi (: Csanád); Erdelji (: Erdély); Fehervari (: Fehérvár), Gadanec (: Gadány); Horvat, Horvatek, Horvatić (: Hrvatska); Kanižaj (: Kanizsa); Kisegi (: Kőszeg); Mađar, Mađarević, Mađarić (: Mađarska); Murakezi (: Muraköz 'Međimurje'); Ostrognaj, Ostrognjaj, Ostrogonac (: Ostrogon); Peči (: Pécs), Peštanac, Peštaj (: Pešta); Požgaj (: Požega); Segedi (: Szeged); Sigeti (: Sziget); Siladi (: Szilád); Šikloši (: Siklós); Šurdi (: Surd); Tolnaj (: Tolna); Ujlaki (: Újlák)...

Prezimena etničkoga i etnonimskoga postanja svjedoče o migracijama do kojih je - u razdoblju formiranja prezimena, ali i u prezimenskome razdoblju - dolazilo na hrvatskome prostoru. Čestotnošću se izdvajaju prezimena nastala od etnika mađarske tvorbe (sufiksom - $i$, odnosno njegovom pohrvaćenom inačicom -j koja dolazi na ojkonimske likove vokalnih završetaka). Posebno mjesto u ovoj skupini prezimena zauzima poprezimenjeni etnonim Horvat (i izvedenice od njega nastale), najčestotnije hrvatsko prezime „rasprostranjeno isključivo na kajkavskom području, odnosno na području nekadašnje Slavonije“, gdje je u srednjovjekovlju narodno ime rijetko potvrđeno te „rano nastaju najbrojnija prezimena Horvat, i druga u vezi s njim, kao osvjedočenje pripadnosti njihovih nositelja hrvatskoj etniji i u očima njihovih sjevernih susjeda, koji su obliku prezimena Horváth dali svoj jezični biljeg“(Šimunović 2006: 386).

\section{d) prezimena od naziva zanimanja ${ }^{7}$}

Biro, Birov, Birovčec (: bíró 'sudac'); Čordaš, Čordašić (: csordás 'pastir'); Doboš, Dobošević (: dobos 'bubnjar'); Dudaš, Dudašek (: dudás 'gajdaš'); Eršek (: érsek 'nadbiskup'); Feletar (: feletar 'kočijašev pomoćnik'); Gazda, Gazdek, Gazdić (: gazda 'domaćin; posjednik, gospodar'); Alasić, Alasović, Halas, Halasz (: halász 'ribar'); Hegediš, Hegeduš, Hegedušić (: hegedüs 'violinist; guslač'); Herceg (: herceg 'vojvoda; knez'); Katana, Katančić, Katanec (: katona 'vojnik'); Kedmenec (: ködmön 'kožuh'; 'kožuhar'); Kočiš (: kocsis 'kočijaš'); Kuhta, Kuhtić (: kuhta 'kuharski pomoćnik'); Mesaroš (: mészáros 'mesar'); Mešter, Meštrović (: mester 'majstor'); Paler, Palir (: paler, palir 'građevinski poslovođa, nadglednik'); Bandur, Pandur, Pandurević, Pandurić (: pandúr 'pandur, stražar'); Pišpek (: püspök 'biskup'); Sabo, Szabo, Sabol, Sabolčec, Sabolek (: szabó 'krojač'); Sokač, Sokačić (: szakács 'kuhar'); Šipoš, Šipuš, Šipušić (: sípos, sípus ‘svirač'); Vadas (: vadász 'lovac’); Vajda, Vajdić (: vajda ‘vojvoda'); Varga, Vargec, Vargek, Vargović (: varga 'postolar')...

7 U tu su skupinu uvršteni i nazivi koji se odnose na državnu te crkvenu hijerarhiju, položaj u društvu, titule, funkcije i sl. iako neki od njih sigurno nisu bili oznakom stvarnoga položaja/ službe njihovih prvih nositelja. Prezimena s nazivom predmeta u osnovi uglavnom se dovode u vezu s osobama koje ih izrađuju (npr. Kedmenec < ködmön 'kožuh'; 'kožuhar'). 
Nazivi zanimanja neizostavnom su sastavnicom prezimenske građe, te ih, obilno zastupljene, nalazimo i među prezimenima temeljenim na mađarskim leksemima. Mnogi od njih potvrđeni su u hrvatskim jezikom pisanim starijim izvorima, a rijetki su dijelom aktivnoga rječnika govornika hrvatskoga jezika - većina ih je (uglavnom promjenom izvanjezične zbilje, tj. nestankom zanimanja njima nazvanih) prešla u kategoriju historizama.

\subsection{Tvorbena klasifikacija prezimena}

Iz tvorbene raščlambe izostavit će se hrvatskomu jeziku grafijski neprilagođena prezimena te prezimena tvorena prepoznatljivim mađarskim sufiksima (prezimenskim i etničkim). Ostala, kudikamo brojnija, prezimena tvorbeno se dijele na:

\section{a) asufiksalna prezimena}

aa) nastala onimizacijom apelativnih leksema (npr. Birov, Halas, Katana, Kuhta, Sokac). Apelativi su u hrvatski jezik posuđeni u doprezimenskome razdoblju, te su $\mathrm{u}$ vrijeme formiranja hrvatskih prezimena, ravnopravno s iskonskim hrvatskim apelativnim leksikom, sudjelovali u prezimenskoj (asufiksalnoj i sufiksalnoj) tvorbi. ${ }^{8}$ Dosadašnja istraživanja hrvatskoga povijesnog (Hadrovics 1985) i suvremenoga dijalektnog leksika (npr. Blažeka 2006, Jakšić 2015, Lipljin 2002) potvrđuju njihovu zasvjedočenost $\mathrm{u}$ apelativnome leksiku hrvatskih govora.

ab) nastala transonimizacijom osobnih imena (npr. Balaž, Balent, Ferenc, Ištvan, Janoš, Kelemen, Matjaš, Pal, Pongrac), nadimaka (npr. Balog, Kiš, Kopas, Nađ, Šovanj, Vereš) te etnika i etnonima (Budimac, Horvat, Mađar, Ostrogonac, Peštanac)

\section{b) sufiksalna prezimena}

Ta su prezimena tvorena prepoznatljivim hrvatskim prezimenskim sufiksima. Oni uvijek dolaze na osnovu prilagođenu hrvatskomu jeziku.

-(č)ić Antolić, Antolčić, Farkašić, Ištvanić, Janošić, Katalinić, Kelemenić, Lukačić, Pongračić, Žigmundić; Feketić, Kopasić; Čordašić, Gazdić, Hegedušić, Katančić, Lovasić; Budimčić, Mađarić, Horvatić...

-ović/-ević Antolković, Balentović, Janošević, Lukačević, Šandorović; Balogović; Hajduković, Meštrović, Vargović; Mađarević...

-ek Antolek, Janošek; Dudašek, Husarek, Sabolek, Vargek; Horvatek...

-(̌̌c)ec Antolec, Matjašec; Birovčec, Katanec, Sabolčec, Vargec...

Prezimenske tvorenice s hungarizmom u osnovi ni po čemu se ne razlikuju od ostaloga sufiksacijom nastaloga hrvatskog prezimenika - u tvorbi sudjeluju sve motivacijsko-semantičke skupine; najčešći prezimenski sufiksi jesu -ić, -ović/-ević, -ec i -ek; nerijetko se

8 Da su navedni leksemi bili posuđeni kao apelativi, dokazom su i (imeničke, pridjevske, glagolske) tvorenice od njih te sintagme čijom su sastavnicom (npr. birov, birovina, birovski, mali birov; (h)alas, alasiti, halasina, alaski; katana, katanica, katančić, katanija, katanski; kuhta, kuhtič, kuhtić; sokač, sokačić, sokačic, sokačica, sokačija, sokačtvo, sokačnica, sokački, sokačka knjiga, sokačiti; Hadrovics 1985). 
istoj osnovi dodaju različiti sufiksi (npr. Sabolić, Sabolčić, Sabolec, Sabolčec, Sabolek) čime se postiže razlikovnost prezimenskoga znaka, a to pak pridonosi preciznijemu označivanju imenovane osobe.

\section{ZAKLJUČAK}

U više od osam stotina godina dugoj zajedničkoj povijesti Hrvata i Mađara pretkazivo je dolazilo do jezične interferencije i obostranoga jezičnog posuđivanja kojemu preprekom nije bila genetska i tipološka različitost njihovih jezika. Posuđivalo se na apelativnoj i imenskoj razini. Brojni su hungarizmi i danas sastavnicom hrvatskoga nestandardnojezičnoga, mahom dijalektnoga, leksika, a dio njih ugrađen je u hrvatski prezimenski mozaik. Petrificirani u prezimenskim strukturama - nepromjenjivim, nasljednim i zakonom propisanim identifikacijskim oznakama - potonji su hungarizmi dijelom specifičnoga (imenskoga) standardnojezičnog leksika. Tako je npr. hungarizam halas ('ribar') dijalektizam te u mnogim organskim idiomima zastarjelica, a njegov homofonijski ,prezimenski parnjak“ Halas, sveden na značenje 'prezime', sastavnicom je standardnojezične komunikacije.

Uočljiva prošaranost hrvatskoga prezimenika hungarizmima te njihova prisutnost i u ostalome dijelu hrvatske onimije, pozivom su na daljnja istraživanja kojima će se unijeti više svjetla u mozaik hrvatsko-mađarske dodire zasvjedočene imenima.

\section{Literatura}

I.

BLAŽEKA, Đuro (2006) „Hungarizmi u govoru Goričana.“ Suvremena lingvistika 1, $1-27$.

DÜRRIGL, Marija-Ana (1988) „Hungarizmi u hrvatskom književnom jeziku.“ Jezik 35/4, 97-99.

FRANČIĆ, Anđela/Orsolya ŽAGAR-SZENTESI (2008) „Međimurska ojkonimija na mađarski način." Folia onomastica Croatica 17, 59-80.

GULEŠIĆ, Milvia (1998) „Još jednom o hungarizmima u hrvatskome standardnom jeziku." U: K. Gadanji (ur.), VI međunarodni slavistički dani, knj. 3/1. Sambotel/ Pečuh: Hrvatski znanstveni zavod, 255-261.

HADROVICS, László (1985) Ungarische Elemente im Serbokroatischen. Köln/Wien: Böhlau Verlag.

JAKŠIĆ, Martin (2015) Rječnik govora slavonskih, baranjskih i srijemskih. Zagreb: Dominović.

LIPLJIN, Tomislav (2002) Rječnik varaždinskoga kajkavskog govora. Varaždin: Garestin. MERŠIĆ, Žuža/Milvia GULEŠIĆ (1997) „Mađarski „dalmatizmi“ po Vrančiću.“ U: S. Blažetin (ur.), Hrvati i Mađari u svjetlu prožimanja kultura i jezika, knj. 2. Pečuh: Hrvatski znanstveni zavod, 220-223.

NYOMÁRKAY, István (1989) Ungarische Vorbilder der kroatischen Spracherneuerung. Budapest: Akadémiai Kiadó. 
Obiteljski zakon (2014) Narodne novine 75/14.

ŠIMUNOVIĆ, Petar (2006) Hrvatska prezimena. Zagreb: Golden marketing/Tehnička knjiga.

ŠIMUNOVIĆ, Petar/Franjo MALETIĆ (prir.) (2008) Hrvatski prezimenik: Pučanstvo Republike Hrvatske na početku 21. stoljeća. Zagreb: Golden marketing/Tehnička knjiga.

ŠIMUNOVIĆ, Petar/Valentin PUTANEC (1976) Leksik prezimena Socijalističke Republike Hrvatske. Zagreb: Institut za jezik/Nakladni zavod Matice hrvatske.

VULIĆ, Sanja (2012) „O imenici varoš u čakavštini, štokavštini i kajkavštini.“ Čakavska rič 1-2, 13-20.

Zakon o osobnom imenu. Narodne novine 118/12.

ŽAGAR-SZENTESI, Orsolya (2005) „Hrvatski u dodiru s mađarskim jezikom.“ U: L. Sočanac (ur.), Hrvatski jezik u dodiru s europskim jezicima: prilagodba posuđenica. Zagreb: Nakladni zavod Globus, 51-84.

ŽAGAR-SZENTESI, Orsolya (2009) ,Slavonski jezični prostor iz hungarološkog aspekta." U: A. Bilić (ur.), Šokačka rič 6. Vinkovci: Zajednica kulturno-umjetničkih djelatnosti Vukovarsko-srijemske županije, 69-84.

II.

FERCSIK, Erzsébet/Judit RAÁTZ (2009) Keresztnevek enciklopédiája: A leggyakoribb női és férfinevek. Budapest: Tinta Könyvkiadó.

FILIPOVIĆ, Rudolf (1986) Teorija jezika u kontaktu: uvod u lingvistiku jezičnih dodira. Zagreb: JAZU/Školska knjiga.

FRANČIĆ, Anđela (2005) „Hungarizmi u međimurskim prezimenima.“ U: S. Lukač (ur.), Na brzu ruku skupljeni skup. Budimpešta: Hrvatska samouprava Budimpešte, 153-162.

HAJDÚ, Mihály (2003) Általános és magyar névtan. Budapest: Osiris Kiadó.

HAJDÚ, Mihály (2010) Családnevek enciklopédiája: Leggyakoribb mai családneveink. Budapest: Tinta Könyvkiadó.

KÁZMÉR, Miklós (1993) Régi magyar családnevek szótára XIV-XVII század. Budapest: Magyar Nyelvtudományi Társaság.

Rječnik hrvatskoga kajkavskoga književnog jezika. Ur. B. Finka/R. Katičić. Knj. 1-13. Zagreb: Hrvatska akademija znanosti i umjetnosti/Institut za hrvatski jezik i jezikoslovlje, 1984- 2014.

STOLAC, Diana (1997) „Starija hrvatska leksikografija i mađarski jezik.“ U: S. Blažetin (ur.), Hrvati i Mađari u svjetlu prožimanja kultura i jezika, knj. 2. Pečuh: Hrvatski znanstveni zavod, 249-257.

SUČEVIĆ MEĐERAL, Krešimir/Tatjana VUKADINOVIĆ/Irina JUROVIĆ/Margit Bernadett VUK (2013) Mađarsko-hrvatski rječnik. Zagreb: Institut za hrvatski jezik i jezikoslovlje. 


\section{Sažetak \\ ODSLIK HRVATSKO-MAĐARSKIH DODIRA U HRVATSKIM PREZIMENIMA}

U uvodnome dijelu rada autorica se kratko osvrće na povijest hrvatskih prezimena te na hrvatsko-mađarske jezične dodire i njihovo proučavanje. Pretkazivi rezultat višestoljetnoga državnog zajedništva Hrvata i Mađara jesu i hungarizmi, od kojih je samo manji dio sastavnica leksika hrvatskoga standardnog jezika (npr. bunda, cikla, cipela, čipka, čopor, karika, kočija, korov, lopov, palačinka, šator, soba). O hrvatsko-mađarskim dodirima na svoj specifičan način svjedoči i hrvatska onimija (npr. ojkonimi Madžarevo, Banfi, Daruvar, Varaždin, Laslovo, Farkaševac). Dio onimijske ukupnosti jesu i prezimena temeljena na mađarskim elementima (npr. Balog, Gazdić, Janušić, Kanižaj, Matjašec, Nagy, Palfi, Pišpek, Pongračić, Sabolčec, Vargek). Središnji je dio rada motivacijsko-semantička i tvorbena klasifikacija u hrvatskome prezimenskom fondu zasvjedočenih prezimena s mađarskim elementima popraćena odabranim primjerima. Uzimajući u obzir stupanj prilagođenosti u prezime ugrađenih mađarskih leksema hrvatskomu jeziku, tvorbenu strukturu tih prezimena, potvrđenost leksika mađarskoga podrijetla u hrvatskoj povijesnoj leksikografiji i sadašnjim hrvatskim govorima - pretpostavlja se da su neka na hungarizmima temeljena prezimena nastala u Hrvatskoj, a neka su u različitim razdobljima unesena u hrvatski prezimenik doseobom svojih nositelja. U zaključnome se dijelu rada, uz ostalo, ističe potreba daljnjega popisivanja i istraživanja hungarizama u hrvatskim nestandardnojezičnim govorima te u svekolikome imenskom mozaiku.

Ključne riječi: hrvatska prezimena, hrvatsko-mađarski jezični dodiri, jezično posuđivanje, hungarizmi

\section{Abstract \\ CROATIAN-HUNGARIAN CONTACTS REFLECTED IN CROATIAN SURNAMES}

In the introductory part of the paper the author briefly comments on the history of Croatian surnames, on Croatian-Hungarian language contact and studies of these contacts. A predictable result of centuries-long political union of Croats and Hungarians are Hungarianisms, of which only a smaller part belongs to standard Croatian lexis (e.g. bunda, cikla, cipela, čipka, čopor, karika, kočija, korov, lopov, palačinka, šator, soba). Croatian anthroponymy likewise testifies to the Croatian-Hungarian contact in its own right, both through oikonyms (e.g. Madžarevo, Banfi, Daruvar, Varaždin, Laslovo, Farkaševac) and surnames based on Hungarian elements (e.g. Balog, Gazdić, Janušić, Kanižaj, Matjašec, Nagy, Palfi, Pišpek, Pongračić, Sabolčec, Vargek). The core of the paper deals with the classification of Croatian surnames which contain Hungarian elements, from the perspective of their formation and semantic motivation together with illustrative examples. Taking into consideration the degree to which Hungarian lexemes present in a given surname have been adapted to the Croatian language, the way 
in which these surnames were formed, all the confirmed instances of Hungarian lexis in Croatian historical lexicography and current Croatian dialects - it is suggested that some of the surnames are based on Hungarianisms originating in Croatia, while some were introduced into the pool of Croatian surnames at different time periods, when their bearers arrived in Croatia. The paper emphasizes, among other things, the need for further identification and research of Hungarianisms in non-standard Croatian dialects as well as in the inventory of personal names.

Keywords: Croatian surnames, Croatian-Hungarian linguistic contacts, linguistic borrowing, Hungarian loanwords

\section{Povzetek \\ ODRAZ HRVAŠKO-MADŽARSKIH STIKOV V HRVAŠKIH PRIIMKIH}

V uvodnem delu prispevka se avtorica na kratko dotakne zgodovine hrvaških priimkov in hrvaško-madžarskih jezikovnih stikov ter njihovega proučevanja. Predvidljiv rezultat večstoletne državne skupnosti Hrvatov in Madžarov so tudi hungarizmi, od katerih samo manjši del spada v leksiko hrvaškega knjižnega jezika (npr. bunda, cikla, cipela, čipka, čopor, karika, kočija, korov, lopov, palačinka, šator, soba). O hrvaško-madžarskih stikih na specifičen način pričajo tudi hrvaška lastna imena (npr. naselbinska imena Madžarevo, Banfi, Daruvar, Varaždin, Laslovo, Farkaševac). Del lastnoimenskih stičǐšč so tudi priimki, ki slonijo na madžarskih prvinah (npr. Balog, Gazdić, Janušić, Kanižaj, Matjašec, Nagy, Palfi, Pišpek, Pongračić, Sabolčec, Vargek). Osrednji del prispevka je motivacijsko-semantična in tvorbena klasifikacija priimkov z madžarskimi prvinami, izpričanih v hrvaškem priimkovnem fondu, opremljena z izbranimi primeri. Glede na stopnjo prilagojenosti v priimek vgrajenih madžarskih leksemov hrvaškemu jeziku, na tvorbeno strukturo teh priimkov, na izpričanost leksike madžarskega izvora v hrvaški zgodovinski leksikografiji in sedanjih hrvaških govorih, se predpostavlja, da so nekateri na hungarizmih sloneči priimki nastali na Hrvaškem, nekateri pa so se v različnih obdobjih uvrstili med hrvaške priimke s priselitvijo svojih nosilcev. V sklepnem delu prispevka se med drugim poudarja potreba nadaljnjega popisovanja in raziskovanja hungarizmov v hrvaških neknjižnojezikovnih govorih in v celotnem imenskem mozaiku.

Ključne besede: hrvaški priimki, hrvaško-madžarski jezikovni stiki, medjezikovno izposojanje, madžarizmi 